\title{
PHENOLIC CONTENTS AND ANTIOXIDANT ACTIVITY IN CENTRAL-SOUTHERN URUGUAYAN PROPOLIS EXTRACTS
}

\author{
MARGOT PAULINO ZUNINI I* CRISTHIAN ROJAS ${ }^{1,3}$, SEBASTIÁN DE PAULA ${ }^{2}$, IGAL ELINGOLD ${ }^{4}$, \\ ELENA ALVAREDA MIGLIARO ${ }^{I}$, MARTA B. CASANOVA ${ }^{4}$, FEDERICO IRIBARNE RESTUCCIA ${ }^{l}$, \\ SARA AGUILERA MORALES ${ }^{3}$, MARTA DUBIN ${ }^{4}$
}

\author{
${ }^{1}$ - Laboratorio de Bioinformática y Farmacoquímica Molecular - DETEMA - Facultad de Química; Universidad de la República - \\ UdelaR; General Flores 2124, 11600. Montevideo, Uruguay \\ 2 - Laboratorio de Farmacogonosia y Productos Naturales - DQO- Facultad de Química; Universidad de la República - \\ UdelaR; General Flores 2124, 11600. Montevideo, Uruguay \\ 3 - Departamento de Física, Facultad de Ciencias, Universidad Católica del Norte, Avda. Angamos 0610, Antofagasta, Chile \\ ${ }^{4}$ - Centro de Estudios Farmacológicos y Botánicos (CEFYBO) CONICET, Facultad de Medicina, Universidad de Buenos Aires, \\ Paraguay 2155, 1121 - Buenos Aires. Argentina \\ Current address: Departamento de Ciencias Químicas y Farmacéuticas, Facultad de Ciencias, Universidad Católica del Norte, \\ Avda. Angamos 0610, Antofagasta, Chile
}

(Received: August 26, 2009 - Accepted: October 7, 2009)

\begin{abstract}
A study on the phenolic content and antioxidant properties of Uruguayan propolis is presented. Identification and quantification was carried out by Reverse Phase High Performance Liquid Chromatography (RP-HPLC). Antioxidant activity was determined by Antiradical Activity Determination (AAD) measured with DPPH and Microsomal Lipid Peroxidation (MLP) assays. Two phenolic acids (gentistic and $p$-coumaric) and eight flavonoids (fisetin, myricetin, luteolin, quercetin, kaempferol, pinocembrin, chrysin and tectochrysin) were identified. The existence of five other phenols is postulated. The large difference between range of values of scavenger activity AAD (between $60 \%$ and $100 \%$ ) as compared with lipoperoxidation inhibition (between $15 \%$ and $92 \%$ ), suggests that the complexity of the biologic matrix could modulate the antioxidant effect. From a commercial standpoint, research such as the one presented here endows the product with added value, making it more appealing to the interest of industry and entrepreneurs.
\end{abstract}

Keywords: RP-HPLC, phenols, antioxidant activity, propolis

\section{INTRODUCTION}

Propolis is a wax-like resinous substance collected by honey bees from tree buds or other botanical sources that is used as cement and to seal cracks or open spaces in the hive. Its colour varies from green to brown and reddish, depending of the botanical source. Traditionally, beekeepers assumed that bees sealed the cracks and joints of the beehive with propolis to protect the colony from certain elements (like rain) and prevent drafts during the wintertime. More recent research suggests that bees not only survive, but thrive with increased ventilation during the winter in most temperate regions of the world. Propolis is now thought to reinforce the structural stability of the hive, reduce vibration and make the hive more defensible by sealing alternate entrances. Bees may also use it to prevent the existence of diseases and parasites in the hive. They normally carry waste (dead larvae, etc.) out of and away from the hive. However if, for example, a mouse chews its way into the hive for a winter nest and dies, the bees will be unable to move it out through the hive entrance. Instead, they are known to seal the carcass in propolis, effectively mummifying the mouse.

The propolis contains phenolic bioactive molecules. Phenols are present in the human diet and have antioxidant, anti-inflammatory, antitrombotic, antialergic, antiviral and vascular damage preventing effects. There are a number of clinical and nutritional studies about these antioxidant properties ${ }^{1-13}$. Pharmacological properties related to its antioxidant capacity are being evaluated, but little is known as yet ${ }^{14,15}$. Recent studies on natural products, indicate that the phenolic content and antioxidants properties are related to the type and content of phenols ${ }^{16,17}$.

We know, from previous studies that propolis is a natural product of varying composition, depending on geographical origin ${ }^{18-26}$. In particular, phenol type and content have already been described as very variable ${ }^{27-32}$. Kumazawua et al ${ }^{18}$, showed that for various samples collected in Argentina, Austria, Brazil, Bulgaria, Chile, China, Hungary, New Zealand, South Africa, Thailand, Ukraine, Uruguay, the USA and Uzbekistan, the antioxidant activity of propolis may be compared and combine these data with chemical analysis. These and other authors found that the kind of phenols as well as their content in such natural products is very variable ${ }^{27-32}$.

Also, from these studies one may conclude that the antioxidant activity is correlated with the concentration of phenolic acids and flavonoids (flavonols, flavones and flavanones mainly).
Reverse Phase High Performance Liquid Chromatography (RP-HPLC) ${ }^{27-29}$ is an optimal technique to analyze the contents of phenols in natural products. It has been used in the study of a lot of compounds which include sugars, hydrocarbons, lipids, proteins, amino acids, fatty acids, anthocyanins, antihistamines, analgesics, drugs, vitamins, polymers, insecticides ${ }^{33}$ Kumazawa et al ${ }^{18}$ successfuly identified the major constituents of propolis by means of HPLC with photo-diode array and mass spectrometric detection. Therefore, we decided to apply the same technique in our study.

In the same context, both Antiradical Activity (AAD) measured with 2,2-diphenyl-1-picryl-hydrazyl (DPPH) and Microsomal Lipid Peroxidation (MLP) assays have proven useful to study the antioxidant capacity of these compounds ${ }^{34-40}$.

Uruguayan propolis has been studied in the past. Thus, we considered interesting to extend the study to include several geographical regions of Uruguay. This paper presents the results of samples, mainly collected in the central and southern regions of Uruguay, in regards the antioxidant capacity of the phenolic compounds (which are constituents of the ethanolic extracts) combining different techniques such as RP-HPLC, AAD and MLP quantitative determinations.

\section{Chemicals}

\section{EXPERIMENTAL}

Reagents used were: hexane, ethanol and methanol (Merck $\left.{ }^{\mathbf{T M}}\right)$; methanol Merck ${ }^{\mathbf{T M}}$ grade HPLC grade and MiliQ ${ }^{\mathbf{T M}}$ water. Standards of chrysin, $p$-coumaric acid, fisetin and gentistic acid were bought from Aldrich ${ }^{\mathbf{T M}}$. The rest of standards were kindly donated by fellow researchers. Thiobarbituric acid (TBA), Nicotinamide adenine dinucleotide phosphate (NADP), 2,2-diphenyl-1picryl-hydrazyl (DPPH), Adenosine diphosphate (ADP), glucose-6 phosphate (G6P) and glucose 6 phosphate dehydrogenase (G6PDH) were bought from Sigma $^{\mathbf{T M}}$. All other chemicals were analytical grade.

\section{Preparation of samples and standard compounds}

\section{Sample preparation}

Nineteen propolis samples were collected in Central-southern Uruguay. The ethanolic extract of propolis was prepared according to Park et al ${ }^{41-45}$ : 8 $\mathrm{g}$ of propolis were extracted in $100 \mathrm{~mL}$ of EtOH $95 \%$ in a Soxhlet extractor. A solution containing $4 \%+/-2 \%$ average of solid materials was obtained. Note that, depending on the origin of samples, a variable quantity of waxes, resins 
and other insoluble compounds may be present thus the concentration should be estimated in the range $2 \%$ to $6 \%$. Then, a $20 \mathrm{~mL}$ volume of samples of ethanolic propolis extracts were mixed with the same volume of hexane to separate the fatty propolis components and to avoid eventual polimerization. In a second step, $1 \mathrm{~mL}$ of the remaining ethanolic phase was placed in a 20 $\mathrm{mL}$ flask, and evaporated to dryness. Finally, the propolis concentration was disolved in $10 \mathrm{~mL}$ of a mixture of $30 \% \mathrm{MiliQ}^{\mathbf{T M}}$ water and $70 \%$ of HPLC methanol. Thereafter, $2 \mathrm{~mL}$ of the propolis mixture sample was obtained and filtered with a Teflon ${ }^{\mathbf{T M}}$ filter (Advantec MFS $0,2 \mu \mathrm{m}$ ) to eliminate methanol soluble impurities that could damage the column.

Preparation of chemical standards. The standard solutions were prepared using ethanol to dissolve the chemicals described above, to reach concentrations of: $20.32 ; 20.00 ; 21.20 ; 19.52$ and $19.68 \mathrm{mg} / \mathrm{mL}$ of querecetin, tectochrysin, myricetin, kaempferol and luteolin, respectively and $5 \mathrm{mg} / \mathrm{mL}$ of fisetin, chrysin, p-coumaric and gentistic acids.

RP-HPLC procedure: Analysis of flavonoids and other phenolic compounds from ethanolic extracts of propolis and red resinous exudates were performed by RP-HPLC ${ }^{41}$ using a chromatograph equipped with an YMC Pack ODS-A column (RP-18, column size $4.6 \times 250 \mathrm{~mm}$; particle size $5 \mu \mathrm{m}$ ) and a photodiode array detector (SPD-M10A, Shimadzu Co.). The column was eluted using a linear gradient of miliQ water (solvent A) and methanol (solvent B), starting with $30 \%$ B (0-15 min) and increasing to $90 \%$ B (15-75 min), held at $90 \%$ B (75-95 $\mathrm{min})$ and decreasing to $30 \% \mathrm{~B}(95-105 \mathrm{~min})$ with a solvent flow rate of $1 \mathrm{~mL} / \mathrm{min}$. Chromatograms were recorded at $268 \mathrm{~nm}$ with the photodiode array detector. The wavelength was selected according to the absorption spectrum of the standard compounds ${ }^{41}$.

Microsomal preparations. Throughout experiments, authors made sure that animal care was of highest priority, minimizing pain and/or distress, and that the number of individuals involved was strictly limited to those essential to the experimental design. Liver microsomes were isolated from adult male Wistar rats (240-280g). The liver of overnight fasted adult animals was removed and placed quickly in an ice-bath. Microsomes were obtained by differential centrifugation ${ }^{36-38}$

Briefly, the liver tissue was homogenized in $50 \mathrm{mM}$ Tris- $\mathrm{HCl}, 150 \mathrm{mM}$ $\mathrm{KCl}(\mathrm{pH} 7.4)$ (4 mL buffer/g liver). Centrifugation at $600 \mathrm{~g}$ for $10 \mathrm{~min}$ and then at $10800 \mathrm{~g}$ for $15 \mathrm{~min}$ was done to eliminate nuclear and mitochondrial fractions, respectively. The microsomal fraction was obtained by centrifugation of the supernatant at $105,000 \mathrm{~g}$ for $60 \mathrm{~min}$. The microsomal pellet was washed with $150 \mathrm{mM} \mathrm{KCl}$ and either used immediately or stored in liquid nitrogen for 3 months. All procedures were performed at $4^{\circ} \mathrm{C}$. No superoxide dismutase or catalase activities were found in the microsomal suspension (data not shown).

Assay of Microsomal Lipid Peroxidation (MLP). For the assay of NADPH-dependent lipid peroxidation, the incubation mixture consisted of liver microsomes ( $1 \mathrm{mg}$ protein $/ \mathrm{mL})$, the NADPH-generating system $(0.55 \mathrm{mM}$ $\mathrm{NADP}^{+}, 5.5 \mathrm{mM}$ G6P, 1.4 units/mL G6PDH, $5.5 \mathrm{mM} \mathrm{MgCl}_{2}$ ), as the reductant system for microsomal electron transfer, $1.7 \mathrm{mM} \mathrm{ADP}, 0.1 \mathrm{mM} \mathrm{FeCl}_{3}$ (as the iron catalyst), $130 \mathrm{mM} \mathrm{KCl}$ and $23 \mathrm{mM} \mathrm{Na}_{2} \mathrm{HPO}_{4}-\mathrm{KH}_{2} \mathrm{PO}_{4}$ buffer, $\mathrm{pH}$ 7.4. After thermal equilibration at $37^{\circ} \mathrm{C}$, the reaction was started by adding $\mathrm{G} 6 \mathrm{PDH}$ and incubated for $60 \mathrm{~min}$ aerobically in a water bath with shaker $(90 \mathrm{cycles} / \mathrm{min}$ ) at $37^{\circ} \mathrm{C}$ under air. The ethanolic propolis were added to the incubation mixture Controls received the same volume of solvent (ethanol) whose concentration never exceeded $1 \%(\mathrm{v} / \mathrm{v})$; ethanol failed to affect the rate of lipid peroxidation. Malondialdehyde (MDA) content of these samples was measured by the TBA method ${ }^{27}$. Absorbance was measured spectrophotometrically at $535 \mathrm{~nm}$ and the amount of MDA was calculated using $\varepsilon=1.56 \times 10^{5} \mathrm{M}^{-1} \cdot \mathrm{cm}^{-1}$.

Antiradical Activity Determination (AAD). Scavenging of free radicals was tested in a methanolic solution of DPPH ${ }^{12}$. The degree of solution decoloration indicates the scavenging efficiency of the substance added. DPPH is a stable free radical and accepts an electron or hydrogen to become a stable diamagnetic molecule ${ }^{40}$. For each compound, aliquots of $1 \mathrm{~mL}$ standard compounds and propolis extracts, prepared in ethanol as described, were added to $2 \mathrm{~mL}$ of DPPH solution $(10 \mathrm{mg} / \mathrm{L})$. Fifteen minutes later, the reduction capability of DPPH radicals was determined by the decrease in absorbance at $517 \mathrm{~nm}$. A reference sample was prepared with $1 \mathrm{~mL}$ of ethanol. Antiradical activity was calculated as percentage of DPPH decoloration using the following equation:

$\mathrm{AAD}=100 \times(1-$ absorbance of sample/absorbance of reference $)$
Statistical analysis. The effect of of standard compounds and propolis extracts was calculated taking as the control value the result of the ethanol containing sample. GraphPad Prism version 4.00 (GraphPad Software San Diego; CA, USA) was used to calculate the standard errors of independent experiments involving duplicate analyses for each sample condition. Statistical analysis was done with one-way analysis of variance (ANOVA) test for repeated measurements and either Dunnett or Tukey post-test. Significance was accepted as $\mathrm{p}<0.05$.

\section{RESULTS AND DISCUSSION}

Ten phenols (gentistic and p-coumaric acid, fisetin, myricetin, luteolin, quercetin, kaempferol, pinocembrin, chrysin and tectochrysin) were selected from bibliographic data and used as standard compounds ${ }^{41-46}$ : In Tables 1 and 2 are reported the results of the analysis of RP-HPLC (retention time, concentrations used and maximum absorbances recorded). As it is known, in a reverse phase chromatography, the elution order of the different components is related to their lipophilicity or hydrophobicity. Therefore, there is a clear relationship between structure and order of elution. To understand more deeply this relationship and to predict the elution order of components not yet identified, compound lipophilicity was measured by calculating the $\log \mathrm{P}$, where $\mathrm{P}$ is the octanol/water coefficient. LogP was calculated using MOE package ${ }^{47}$ and with an atomic contribution mode ${ }^{48}$ developed with a training set of about 7000 structures that calculates $\log P$ from the given structure.

Table 1: Results of RP-HPLC analysis of propolis extracts. First column: phenolic acid structures used as standard compounds in the RPHPLC experiment. Second column: (retention time): elution time where the the maximum of absorbance was registered (Third column). Fourth column: phenolic acid concentration used in the experiment. P: octanol/water coefficient.

\begin{tabular}{|c|c|c|c|c|}
\hline $\begin{array}{c}\text { Phenolic Acid } \\
\text { Compound }\end{array}$ & $\begin{array}{c}\text { Retention } \\
\text { time (minutes) }\end{array}$ & $\begin{array}{c}\text { Maximum } \\
\text { Absorbance } \\
(\mathrm{mAU})\end{array}$ & $\begin{array}{c}\text { Concentration } \\
(\mathrm{mg} / \mathrm{mL})\end{array}$ & $\log \mathrm{P}$ \\
\hline Gentistic & 1.533 & 315 & 5 & 1.1230 \\
\hline$p$-Coumaric & 5.420 & 150 & 5 & 2.0400 \\
\hline
\end{tabular}

Table 2: Results of RP-HPLC analysis of propolis extracts. First and second columns: flavonoids used as standard compounds in the RP-HPLC experiment. Numbers in the first row of $3^{\text {th }}$ to $8^{\text {th }}$ columns correspond to the positions in the $\mathrm{A}, \mathrm{B}$ and $\mathrm{C}$ rings currently used for flavones in which the numbering starts in the oxygen pyran of ring $C$. Ring $B$ positions are numbered with quotes. $9^{\text {th }}$ column: (retention time): elution time where the the maximum of absorbance was registered ( $10^{\text {th }}$ column). P: octanol/water coefficient; $12^{\text {th }}$ column: flavonoid concentration used in the experiment . 


\begin{tabular}{|c|c|c|c|c|c|c|c|c|c|c|c|}
\hline Flavonoids & Type & 3 & 5 & 7 & $3^{\prime}$ & $4^{\prime}$ & $5^{\prime}$ & $\begin{array}{c}\text { Retention } \\
\text { times } \\
\text { (minutes) }\end{array}$ & $\begin{array}{c}\text { Absorbance } \\
\text { (mAU) }\end{array}$ & logP & Concentration \\
\hline Fisetin & Flavonol & $\mathrm{OH}$ & --- & $\mathrm{OH}$ & $\mathrm{OH}$ & $\mathrm{OH}$ & & 36.993 & 1300 & 2.305 & $5 \mathrm{mg} / \mathrm{mL}$ \\
\hline Myricetin & Flavonol & $\mathrm{OH}$ & $\mathrm{OH}$ & $\mathrm{OH}$ & $\mathrm{OH}$ & $\mathrm{OH}$ & $\mathrm{OH}$ & 38.529 & 210 & 1.759 & $21.2 \mu \mathrm{g} / \mathrm{mL}$ \\
\hline Luteolin & Flavone & --- & $\mathrm{OH}$ & $\mathrm{OH}$ & $\mathrm{OH}$ & $\mathrm{OH}$ & --- & 46.829 & 380 & 2.261 & $19.68 \mu \mathrm{g} / \mathrm{mL}$ \\
\hline Quercetin & Flavonol & $\mathrm{OH}$ & $\mathrm{OH}$ & $\mathrm{OH}$ & $\mathrm{OH}$ & $\mathrm{OH}$ & --- & 47.093 & 130 & 2.032 & $20.32 \mu \mathrm{g} / \mathrm{mL}$ \\
\hline Kaempferol & Flavonol & $\mathrm{OH}$ & $\mathrm{OH}$ & $\mathrm{OH}$ & --- & $\mathrm{OH}$ & --- & 50.278 & 280 & 2.305 & $19.52 \mu \mathrm{g} / \mathrm{mL}$ \\
\hline Pinocembrin & Flavanone* & --- & $\mathrm{OH}$ & $\mathrm{OH}$ & --- & --- & --- & 52.845 & 820 & 2.688 & $5 \mathrm{mg} / \mathrm{mL}$ \\
\hline Chrysin & Flavone & --- & $\mathrm{OH}$ & $\mathrm{OH}$ & --- & --- & --- & 61.807 & 1300 & 2.842 & $5 \mathrm{mg} / \mathrm{mL}$ \\
\hline Tectochrysin & Flavone & --- & $-\mathrm{OH}-$ & $\mathrm{OMet}$ & --- & --- & -- & 76.054 & 740 & 3.106 & $20.00 \mu \mathrm{g} / \mathrm{mL}$ \\
\hline
\end{tabular}

The identification of the phenolic compounds in the Uruguayan propolis was made by comparing the elution times of the standard compounds and the peaks observed for the nineteen extract samples. Measures for both, the standards and the propolis samples, were obtained in the same conditions as above described. Chromatograms were analyzed in detail and compared with one another. Quantification of the phenols identified is shown in Table 3.

Table 3: Phenol quantification (\%) in ethanolic extracts of propolis samples from South-Central Uruguay

\begin{tabular}{|c|c|c|c|c|c|c|c|c|c|}
\hline Sample & p-Coumaric & Fisetin & Myricetin & Luteolin & Quercetin & Kaempferol & Pinocembrin & Chrysin & Tectochrysin \\
\hline 1 & 0 & 12.32 & 0.43 & 0.06 & 0 & 0.12 & 81.78 & 5.00 & 0.29 \\
\hline 2 & 0 & 0 & 0 & 0 & 0 & 0 & 2.07 & 97.66 & 0.27 \\
\hline 3 & 0 & 0 & 0 & 0 & 0 & 0.31 & 0 & 99.30 & 0.39 \\
\hline 4 & 13.30 & 0 & 0 & 0 & 0 & 0 & 52.98 & 33.61 & 0.11 \\
\hline 5 & 2.13 & 2.57 & 0.42 & 0 & 0.12 & 0.12 & 8.80 & 85.82 & 0.03 \\
\hline 6 & 7.85 & 3.61 & 0.22 & 0.02 & 0 & 0.04 & 42.24 & 46.03 & 0 \\
\hline 7 & 14.05 & 19.35 & 0.58 & 0 & 0 & 0.22 & 59.24 & 6.49 & 0.08 \\
\hline 8 & 16.10 & 7.78 & 0.32 & 0.01 & 0 & 0 & 68.52 & 7.27 & 0 \\
\hline 9 & 11.25 & 3.65 & 0.17 & 0.01 & 0 & 0.02 & 42.15 & 42.75 & 0 \\
\hline 10 & 11.16 & 4.23 & 0.15 & 0.01 & 0 & 0 & 39.17 & 45.27 & 0.02 \\
\hline 11 & 21.98 & 8.31 & 0.03 & 0 & 0.14 & 0.08 & 61.55 & 7.88 & 0.05 \\
\hline 12 & 9.98 & 4.27 & 0.03 & 0.01 & 0 & 0.04 & 40.29 & 45.37 & 0.01 \\
\hline 13 & 8.06 & 5.46 & 0.15 & 0 & 0.01 & 0 & 31.38 & 54.89 & 0.06 \\
\hline 14 & 26.32 & 9.33 & 0.31 & 0.04 & 0 & 0.06 & 59.39 & 4.53 & 0.02 \\
\hline 15 & 8.70 & 4.23 & 0.13 & 0 & 0.02 & 0.02 & 33.48 & 53.36 & 0.05 \\
\hline 16 & 18.56 & 3.33 & 0.06 & 0 & 0 & 0 & 38.59 & 39.46 & 0 \\
\hline 17 & 15.80 & 4.14 & 0.04 & 0 & 0 & 0 & 39.23 & 40.79 & 0 \\
\hline 18 & 33.67 & 5.38 & 0.15 & 0 & 0.06 & 0 & 27.55 & 33.16 & 0.04 \\
\hline 19 & 45.26 & 9.62 & 0.26 & 0 & 0 & 0.12 & 42.67 & 2.02 & 0.06 \\
\hline
\end{tabular}

The results of measurements of MLP and AAD using DPPH radical obtained for standard compounds and propolis extract samples are presented in Tables 4,5 and 6 respectively. 
Table 4. Antiradical Activity Determination (AAD) measured with DPPH and Microsomal lipid peroxidation inhibition (MLP) for the thirteen polyphenolic standards

\begin{tabular}{|c|c|c|c|c|c|}
\hline $\begin{array}{c}\text { Polyphenolic } \\
\text { compound (70 mM) }\end{array}$ & $\begin{array}{c}\text { MLP } \\
\mathbf{\%}\end{array}$ & AAD (DDPH) & OH positions & $\begin{array}{c}\text { Glicosilated } \\
\text { positions }\end{array}$ & $\begin{array}{c}\text { Structural } \\
\text { Family }\end{array}$ \\
\hline Quercetin & 96.4 & 81.74 & $3,5,7,3^{\prime}, 4^{\prime}$ & & Flavonol \\
\hline Pinocembrin & 87.2 & 3.65 & 5,7 & & Flavanone \\
\hline Luteoline & 86.1 & 79.49 & $5,7,3^{\prime}, 4^{\prime}$ & $3^{\prime}$-OMe & Flavone \\
\hline Cafeic acid & 41.4 & 95.46 & 3,4 & & Phenolic acid \\
\hline Genisteíne & 40.3 & 4.09 & $5,7,3^{\prime}$ & & Isoflavone \\
\hline Apigenine & 26.9 & 9.96 & $5,7,4^{\prime}$ & & Flavone \\
\hline Daidzeíne & 20.9 & 2.21 & $7,3^{\prime}$ & & Isoflavone \\
\hline Naringenine & 20.5 & 7.07 & $5,7,4^{\prime}$ & & Flavanone \\
\hline Sinapic Acid & 18.2 & 95.3 & 3 & $2,4-O M e$ & Phenolic acid \\
\hline Ferulic Acid & 15.2 & 94.29 & 3 & 2 -OMe & Phenolic acid \\
\hline Fisetine & 9.4 & 94.17 & $3,7,3^{\prime}, 4^{\prime}$ & & Flavonol \\
\hline$p$-Coumaric Acid & 9.1 & 42.00 & 4 & & Phenolic acid \\
\hline Naringine & 3.8 & 1.19 & $5,7,4^{\prime}$ & & Flavanone \\
\hline
\end{tabular}

Table 5. Microsomal lipid peroxidation (MLP) inhibition of propolis samples from South-Central Uruguay. Samples are ordered according to descendant MLP activity.

\begin{tabular}{|c|c|c|}
\hline $\begin{array}{l}\text { Sample } \\
\text { number }\end{array}$ & $\begin{array}{c}\text { Uruguayan Region / } \\
\text { Geographic Place }\end{array}$ & $\operatorname{MLP}(\%)$ \\
\hline 16 & San José / South & 92.00 \\
\hline 17 & Soriano-Colonia / Southwest & 90.60 \\
\hline 18 & San José / South & 78.90 \\
\hline 5 & Florida / South & 66.10 \\
\hline 4 & Florida / South & 63.40 \\
\hline 3 & Canelones / South & 61.70 \\
\hline 1 & San José / South & 59.30 \\
\hline 6 & Florida / South & 55.50 \\
\hline 19 & Soriano /Southwest & 52.00 \\
\hline 8 & Soriano / Southwest & 45.30 \\
\hline 11 & Colonia / Southwest & 44.10 \\
\hline 12 & San José / South & 43.70 \\
\hline 15 & Soriano / Southwest & 41.08 \\
\hline 10 & Colonia / Southwest & 40.70 \\
\hline 2 & San José / South & 39.10 \\
\hline 13 & Colonia / Southwest & 34.10 \\
\hline 14 & San José / South & 21.70 \\
\hline 9 & Soriano / Southwest & 19.70 \\
\hline 7 & Florida / South & 14.70 \\
\hline
\end{tabular}

Table 6. Antiradical Activity Determination (AAD) using DPPH radical for propolis samples from South-Central Uruguay. Samples ordered according to descendant AAD activity.

\begin{tabular}{|c|c|c|}
\hline $\begin{array}{l}\text { Sample number of } \\
\text { propolis extracts }\end{array}$ & $\begin{array}{c}\text { Geographic origin (Uruguayan } \\
\text { region) }\end{array}$ & AAD \% (DPPH) \\
\hline 19 & Soriano / Southwest & 94.96 \\
\hline 7 & Florida / South & 94.14 \\
\hline 17 & Colonia-Soriano / Southwest & 93.91 \\
\hline 16 & San José / South & 90.70 \\
\hline 18 & San José / South & 90.26 \\
\hline 5 & Florida / South & 89.96 \\
\hline 4 & Florida / South & 89.31 \\
\hline 6 & Florida / South & 87.04 \\
\hline 2 & San José / South & 85.94 \\
\hline 11 & Colonia / Southwest & 84.52 \\
\hline 13 & Colonia / Southwest & 82.72 \\
\hline 1 & San José / South & 78.80 \\
\hline 9 & Soriano / Southwest & 78.41 \\
\hline 14 & San José / South & 78.32 \\
\hline 8 & Soriano / Southwest & 76.44 \\
\hline 15 & Soriano / Southwest & 74.84 \\
\hline 12 & San José / South & 74.57 \\
\hline 3 & Canelones / South & 72.56 \\
\hline 10 & Colonia / Southwest & 63.69 \\
\hline
\end{tabular}


Taking into account the time evolution and the frequency and shape of the peaks on the chromatograms, we can divide the total elution time in five different phases. As expected, there is a clear relationship between retention times and structures: in the first phase phenolic acids were eluted while flavonols (like fisetin, myricetin, quercetin and kaempferol) did so during the second phase, except luteolin which is actually a flavanone. Flavanones (like pinocembrin) eluted during the third phase. In this same phase there are signs for the presence of a phenolic acid derivative, the 1,1-dimethyl-allyl esther of caffeic acid. Finally, peaks for flavones (like chrysin and tectochrysin and possibly galangin as well) appeared during the fourth and fifth phase.

The results suggest that there are at least thirty three different phenols present in the ethanolic propolis extracts. We were able to identify ten of them in an unambiguous way:

Gentistic acid is observed in peaks of high, medium and low intensity. Additionally, taking into account that it is present in three out of nineteen samples, it may be hypothesized that it is a non-frequent component of propolis. p-coumaric acid, is present in sixteen samples. Even if it has low values of MLP \% (9.1\%) and medium AAD capacity (42\%), lower in particular than quercetin and pinocembrin, it is a more frequent compound in propolis as compared gentistic acid. Therefore, p-coumaric acid may be regarded as an important component to characterize Uruguayan propolis as well as to provide a good indication of antioxidant capacity. Fisetin is a flavonol that is also present in sixteen samples. It displays $9.4 \%$ of MLP and $94.17 \%$ of AAD. This could be indicating that fisetin has a positive incidence in propolis antioxidant capacity.Myricetin, another flavonol, appears together with Fisetin in sixteen samples. The coupled elution of these two compounds may be a "fingerprint" of Uruguayan propolis. Luteolin is a flavanone who has been identified in seven samples. It displays $79.49 \%$ of AAD and $86.10 \%$ of MLP. Quercetin is present in five samples and it displays $81.74 \%$ of AAD and $96.4 \%$ of MLP. Kaempferol is a flavonol that eluted in eleven samples. Pinocembrin is a flavanone which is present in eighteen samples and in variable quantities. It is more abundant in samples number 1,8 and 11 . It has a smaller AAD antioxidant capacity than quercetin $(3.65 \%)$ and it is equally good in terms of MLP capacity (87.2\%). Chrysin is a flavone identified in all samples. In sample number 3 it is in high concentration Based on these measurements it is safe to say that chrysin is the major component in Uruguayan propolis. Tectochrysin was identified in fourteen out of nineteen samples.

In view of these results we can say that all extracts are rich in phenolic acids, flavonols, flavones and flavanones, the latter two being the most abundant.

For all the identified phenols except gentistic acid, myricetin, kaempferol, chrysin and tectochrysin, measures of antioxidant capacity were obtained by MPL and AAD techniques.

Quercetin and fisetin, despite being detected at low concentrations of 0.018 and $5.66 \mathrm{mg} / \mathrm{mL}$, respectively, may be contributing in a relevant way to the antioxidant capacity, if we consider that, for example, quercetin has $96.4 \%$ of MLP and $81.74 \%$ of AAD and fisetine has $94.17 \%$ of AAD.

Phenolic acids, which were detected in large numbers too, can make an interesting contribution. For instance, the caffeic acid has an AAD of $95.46 \%$ and a MLP of $41.4 \%$.

As far as the major phenolic components (i.e. pinocembrin and chrysin) goes, it becomes evident that the flavanones and flavones makes the highest impact on the antioxidant contribution of our samples. First, they have a very good ability to inhibit hepatic microsomal lipoperoxidation and/or a very good ability to capture free radicals; this is the case of pinocembrin with a MLP of $97.2 \%$ and luteolin with a MLP of $86.1 \%$ and a $79.49 \%$ of AAD.

Moreover, the presence/absence of the double bond between carbons 2 and 3 of ring $C$, becomes important to explain the high or low AAD rate, like luteolin or pinocembrin respectively. The observed correlation between the antioxidant capacity and the insaturation in the $\mathrm{C}$ ring coincides with many similar results reported earlier in the literature ${ }^{27}$.

Finally, based on our results, we can deduce that a phenolic structure in which positions 5 and 7 are hydroxylated, would confer the extract a strong antioxidant capacity. Examples are the low values of MLP that displayed sinapic, ferulic $p$-coumaric acid and fisetine.

DPPH method was used to test the antioxidant activity of the studied compounds. This method is based on the evaluation of free radical scavenging ${ }^{11}$. In addition, in rat liver microsomes, propolis extracts inhibited the enzymatic lipid peroxidation (Tables 5 and 6). The trapping method using DPPH free radical allows us to assess the reactivity of the flavonoids in a chemical solution, while the MLP assay suggests how to prevent lipoperoxidation in a much more complex scenario than the former, as it is the case of a microsomal solution. The different reactivities found, then allow to appreciate how the structure of phenols is more or less potent in either environment. For example, it is noticeable that the structure of phenolic acids such as those discussed in this paper, is less reactive than the flavonoids when tested with microsomes. This can be interpreted as a difficulty of acids to access or interact with complex structures such as microsomes. However, when measured on a solution as used for the measurement of AAD, the reactivity of phenolic acids is as good or better than that of flavonoids. We hypothesize that the antioxidant activity of phenolic extracts in a complex biological environment such as an entire cell will be better with a higher contents of flavonoids.

Finally, there is a clear relationship between elution times and structures of compounds. Considering that it is well known that retention times depend on the solubility associated with compound structure, we put this to the test for our set of phenols, making a quantitative measure of lipophilicity and relate it with the elution time. To estimate the lipophilicity we used the $\log \mathrm{P}$, a coefficient classically accepted as a good model to measure such property. As shown in Tables 1 and 2, the elution times correlate, in nearly all cases, with lipophilicity. To get quantitative results, we built a QSAR model using MOE package and we found a $90 \%$ correlation between $\log \mathrm{P}$ and retention time. The following correlation equation may be postulated:

Retention time $=6.62+18.76 \log \mathrm{P}$

Equation 1

The equation shows that retention times are directly proportional to $\log \mathrm{P}$ i.e. to compound lipophilicity. In particular, those phenols hydroxylated (at one or two positions) in ring $\mathrm{A}$ and $\mathrm{C}$ and, in addition, are polyhydroxilated in ring $\mathrm{B}$, have lower lipophilicity and consequently displayed lower elution times.

\section{CONCLUSIONS}

Propolis has long been used for the treatment of many pathologies. Therefore, its use in the industry to develop new pharmaceuticals with particular antioxidant or antimicrobial pharmacological profiles should be stimulated. Herein we investigated the properties of Uruguayan propolis. At present, the advance in analytical techniques such as Reverse Phase High Pressure Liquid Chromatography (RP-HPLC) allows one to gain insight on their composition and to study the activity of their components.

In this work, we have shown by chromatographic techniques that it is very likely that the Uruguayan propolis contains as much as thirty different phenols. Indeed, we have identified ten of them: two phenolic acids (gentistic and p-coumaric), fisetin, myricetin, luteolin, quercetin, kaempferol, pinocembrin, chrysin and tectochrysin. The fact that myricetin always eluted together with fisetin could be considered as a fingerprint of Uruguayan propolis. Based on a possible relationship between retention times of some of the unidentified peaks in our chromatograms and bibliographic data, the existence of five other phenols (cinnamic acid, ferulic acid, 1.1-dimethyl-allyl esther of caffeic acid, apigenin and galangin) has been postulated. These latter compounds deserve further investigation in order to be identified in an unequivocal manner.

There is a quantitative relationship between elution times, the structures of compounds and their lipophilicity (Eq 1). It was observed that the higher the $\log \mathrm{P}$ value, the greater its lipophilicity and its elution time, indicating how the structure affects the retention time. In almost all flavonoids, those with more hydroxylated positions, have a lower lipophilicity and, consequently, a lower elution time.

With respect to the AAD determination, polyphenolic standards indicated that phenolic acids together with Fisetine, Quercetine and Luteoline showed more than $50 \%$ of capture. All extracts displayed more than $50 \%$ of antiradical activity.

Microsomal lipid peroxidation measurements showed that two samples have a high lipoperoxidation inhibition and half of the samples presented more than $50 \%$ of lipoperoxidation inhibition. The pure compounds quercetine, pinocembrine and luteoline showed more than $80 \%$ of inhibition at $70 \mathrm{mM}$ concentration.

A possible relationship between structure and lipid peroxidation inhibition may be postulated. The phenolic acid derivatives displayed rather low reactivity, suggesting a negative incidence of charge when reaction takes place in a microsomal environment. Conversely, the negative charge on the derivatives of phenolic acids could be a positive influence and may be associated with an increased scavenger activity.

It is likely that for flavonoids, the relationship is more complex and that it should be necessary to take into account other electronic properties aside charge distribution as well as other kind of factors such as lipophilic and steric traits.

In the case of propolis extracts, the large difference between range of values of scavenger activity (AAD between $60 \%$ and $100 \%$ ) as compared to MLP (between $15 \%$ and $92 \%$ ) suggests that the complexity of the biologic 
matrix could modulate the antioxidant activity.

Finally, we sought for a possible variation of chemical content of propolis extracts in relation to geograpical location. On one hand, if we compare the content and type of phenols found in the Central-southern Uruguay with other countries, as seen in studies of Kumazawa et al (see for example references 15,16 and 17), we can conclude that they are, on average, very similar and that all these studies demonstrate the great diversity of phenol type and content of samples from different origins. On the other hand, in view of our results, it is not possible to separate Southern from Southwestern uruguayan samples. We propose that the Central-Southern, comprising the South and the Southwest regions in Uruguay, be considered as one region. These results evidence the necessity of further investigations to complete the mapping of phenolic compounds and antioxidant activity of Uruguayan propolis becomes clear. To be consistent with this need, we have continued our studies by sampling in the North and Northwestern of Uruguay, regions where the beekeeping activity is intense. We hope that our recent investigations can enrich this discussion in the future.

Finally, from a commercial standpoint, research such as the one presented here endows propolis with added value, making it more appealing to the interest of industry and entrepreneurs.

\section{ACKNOWLEDGEMENTS}

The authors thank beekepers belonging to the Asociación Apícola Uruguaya for providing 19 samples of propolis, TEPYVE S.A. for producing the propolis extracts, Mr. Fernando Castellanos (Fundación Zonamérica) for the diffusion activities, Dr. F. Dajas (Sección Neuroquímica, Instituto Clemente Estable, Uruguay) and Dr. P. Moyna (DQO, Facultad de Química, UdelaR) for providing some of the polyphenol standards. MPZ thanks the Comision Sectorial de Investigación Científica (CSIC) - UdelaR and Ms. Lorena Iorlano Arduini for revising the english language. CR thanks the Students Exchange Program of the Universidad Católica del Norte, Antofagasta, Chile. MD thanks CONICET - Argentine (PIP 6100)

\section{REFERENCES}

1. N. Cotelle, Curr Top Med Chem, 1,569, (2001).

2. C. Amic, D. Davidovic-Amic, D. Besloc, N. Trinajstic, Croat. Chem. Act., 76, 55, (2003).

3. W. Bors, W. Séller, M. Christa, Meth. Enzymol, 186, 343, (1990).

4. P. Cos, L. Ying, M. Calomme, J.P. Hu, Y. Cimanga, B. Van Poel, L. Pieters, A.J. Vlietinck, D. Vanden Berghe, J. Nat. Prod., 61, 71, (1998).

5. B. Havsteen, Biochem. Pharm.,32, 1141, (1983).

6. B. Havsteen, Pharmacol. Ther., 96, 67, (2002).

7. E.R. Lien, S. Ren, H. Bui, R. Wang, Free Radical Biol. Med., 26, 285, (1999).

8. C-M Lin. C-S. Chen, C-T.Chen, Y-C.Liang, J-K.Lin, Bioch. Bioph. Res. Comm., 294, 167, (2002).

9. E. Middleton, Ch. Kandaswami, T.C. Theoharides, Pharmacol. Rev., 52, 673, (2000).

10. B. Modak, M.L. Contreras, F. González-Nilo, R. Torres, Bioorg. Med. Chem. Let., 15, 309, (2005).

11. S. Burda, W. Oleszek, J. Agric. Food Chem., 49, 2774, (2001).

12. O. Farkas, J. Jakus, K. Heberger, Molecules, 9, 1079, (2004).

13. C.A. Rice-Evans, N.J. Miller, G. Paganga, Free Radical Biol. Med., 20, 933, (1996).

14. H. Erhan Ero lu, Y. Zkul, A. Tatlisen, S. Silici, Nat. Prod. Res., 22, 1060 , (2008).

15. M.R. Ahn, K. Kunimasa, S. Kumasawa, T. Nakayama, K. Kaji, Y. Uto, H. Hori, H. Nagasawa, T. Ohta. Mol. Nutr. Food Res. 53, 643, (2009).

16. G. Morales, A. Paredes, P. Sierra, L. A. Loyola. J. Chil. Chem. Soc. 54, $105,(2009)$.
17. A.P.M. Bernardo, J. Chil. Chem. Soc. 52, 1326, (2007).

18. S. Kumazawa, M. Taniguchi, Y. Suzuki, M. Shimura, M.S. Kwon, T. Nakayama, J. Agric. Food Chem., 50, 373, (2002).

19. T. Kumazawa, Hamasaka and T. Nakayama, Antioxidant activity of propolis of various geographic origins, Food Chem., 84, 329, (2004).

20. G. Salamanca Grosso, I. Correa Carvajal, J. Principal, Zootecnia Tropical, 25, 95, (2007).

21. L. Moreira, G. Dias, J.A. Pereira, L. Estevinho, Food Chem. Toxicol., 48, 3482, (2008).

22. L.L. Chaillou, H.A. Herrera, J.F. Maidana, Cienc. Tecnol. Aliment., Campinas, 24, 011, (2004).

23. M.I. Isla, J.F.Paredes-Guzmán, M.I. Nieva-moreno, H. Koo, Y.K. Park, J. Agric. Food Chem., 53, 1166, (2005).

24. E. Bedascarrasbure, L. Maldonado, A. Alvarez, E. Rodriguez, Acta Farm. Bonaerense, 23, 369, (2004).

25. Y.K. Park, S.M. Alencar, C.A. Aguiar, J. Agric. Food Chem., 50, 2502, (2002).

26. I. Chil, S. Pavón, H.Gálvez, C.A. Cuéllar, B. Avila, Rev. Cub. Quím., 14, 34, (2002).

27. Y.K. Park, M. Ikegaki, Biosc., Biotechnol. Biotech., 62, 2230, (1998).

28. J.A. Buege; S.D. Aust, Meth. Enzymol., 52, 302, (1978).

29. S. Kumazawa, T. Hamasaka, T. Nakayama, Food Chem., 84, 329, (2004).

30. J.S. Bonvehí, F.V. Coll, Zeitschrift Natur., 49, 712, (1994).

31. V.S. Bankova, S.L. Castro, M.C. Marcucci, Apidologie, 31, 3, (2000).

32. A.A.L. Mesquita, D. de B Correa, A.P de A. Padua, M.L.O. Guedes, O.R. Gottlieb, Phytochemistry, 25, 1255, (1986).

33. N. Gheldof, X.H. Wang, N.J. Engeseth, J. Agric. Food Chem., 50, 5870, (2002).

34. D.A Skoog, J.J. Leary, Análisis instrumental, $4^{\text {th }}$ Edition; McGraw-Hill: Madrid, España, (1996).

35. M. Dubin, P.H. Carrizo, A.M. Biscardi, S.H. S.H. Fernandez Villamil, A.O.M. A.O.M.Stoppani, Biochem. Pharmacol., 48, 1483, (1994).

36. N. de Witte, A.O.M. Stoppani, M. Dubin, Arch. Biochem. Biophys., 432, $129,(2004)$.

37. M. Dubin, S.H. Fernandez-Villamil, A.O.M. Stoppani, Biochem. Pharmacol., 39, 1151, (1990).

38. S.H. Fernandez-Villamil, M. Dubin, C. Galeffi, A.O.M. Stoppani, Biochem. Pharmacol., 40, 2343, (1990).

39. S.H. Fernandez-Villamil, A.O.M. Stoppani, M. Dubin, Meth. Enzymol., 378, 47, (2004)

40. Z.A. Placer, L.L. Cushman, B.C. Johnson, Anal. Biochem., 16, 359, (1966).

41. L. Mathiesen, K.E. Malterud, R.E. Sund, Free Radical Biol. Med., 22, 307, (1997).

42. Y. K. Park, M. Ikegaki, S. M. Alencar, F. F. Moura, Honeybee Sci., 21, $85,(2000)$

43. Y. K. Park, M. Ikegaki, S. M. Alencar, Mensagem Doce, 58, 2, (2000).

44. Y. K. Park, S. M. Alencar, A. R. P. Scamparini, C. L.Aguiar, Ciencia Rural, Santa Maria, 32, 997, (2002).

45. Y. K. Park, S. M. Alencar, C. L. Aguiar, J. Agric. Food Chem., 50, 2502, (2002).

46. M.I. Isla, J.F. Paredes-Guzman, M.I. Nieva-Moreno, H. Koo, Y.K. Park, Some, J. Agric. Food Chem., 53, 1166, (2005).

47. T. Ackermann, Food Chem., 42, 135, (1991).

48. MOE (The Molecular Operating Environment), Version 2006.08, software available from Chemical Computing Group Inc., 1010 Sherbrooke Street West, Suite 910, Montreal, Canada H3A 2R7, http://www.chemcomp. com.)

49. S.A. Wildman, G.M. Crippen, J. Chem. Inf. Comput. Sci. 39, 868, (1999). 